\title{
Relationship between vitamin D3 level and rheumatoid arthritis patients attending Rizgary Teaching Hospital in Erbil city
}

\section{Abstract}

Background and objective: Rheumatoid arthritis (RA) is an autoimmune disease of unknown etiology. Vitamin D3 plays an important role in bone metabolism and may also have immunomodulatory effects. This study was designed to estimate the prevalence of vitamin $D_{3}$ deficiency in patients with rheumatoid arthritis as compared to healthy controls and to analyze the association between vitamin D3 with disease activity.

Methods: This case-control study included 50 consecutive rheumatoid arthritis patients, who fulfilled EULAR-ACR-2010 and ACR 1987 criteria for Rheumatoid Arthritis, and 50 age matched controls. Their mean age and standard deviation (SD) was $46.42 \pm 10.86$ years. They were not on vitamin D3 supplements. They were selected from the Rheumatology and Medical Rehabilitation Department of Rizgary Teaching Hospital in Erbil City. The activity of disease was assessed by disease activity score and clinical disease activity index parameters. The vitamin D3 was measured for all patients and controls.

Results: A total of 100 participants were enrolled in the study. The vast majority of them were female, and $70 \%$ of cases had deficient vitamin $\mathrm{D}_{3}$ levels, while $46 \%$ of control group suffered from vitamin D3 deficiency $(P<0.05)$. There was a non-significant statistical relationship between vitamin $D_{3}$ levels and duration of disease, disease activity score and clinical disease activity index.

Conclusion: Level of vitamin D3 was low among cases compared to controls and it was statistically significant. Vitamin D3 was not correlated with the disease activity.

Keywords: Rheumatoid arthritis; Vitamin $\mathrm{D}_{3}$; DAS28; CDAl

\section{Introduction}

Rheumatoid arthritis (RA) is an autoimmune disease of unknown etiology. Both $T$ and $B$ lymphocytes have a role in the pathogenesis of the disease. RA is an inflammatory disease characterized by remissions and exacerbation. It is also characterized by symmetrical, destructive and deforming polyarthritis involving small and large synovial joints with associated systemic disturbances, in addition to extra-articular features and the presence of circulating antiglobulin antibodies (rheumatoid factors). The disease activity of RA is assessed by the Disease Activity Score of 28 joints (DAS28). It is an indicator of RA disease activity and response to treatment. The joints included in DAS28 are bilateral: 10 (proximal interphalangeal, metacarpophalangeal joints), 2 (wrists joints, elbows joints, shoulders joints and knees joints). The number of joints with tenderness upon touching (TEN28) and swelling (SW28) are counted. The ESR is measured. Also, the patient makes a subjective assessment (VAS) of disease activity. Vitamin D3 deficiency may increase the risk for the development of RA. ${ }^{1}$ RA is three to five times more in women than in men. ${ }^{2}$ The frequency of disease in developed countries ranges from $0.5-1 \%$ of adults, it mean, 5 to 50 per 100,000 people developing the condition each year. ${ }^{3}$ Vitamin D3 is a secosteroid hormone involved in bone and calcium metabolism.

* Department of Rheumatology and Medical Rehabilitation, Rizgary Teaching Hospital, Erbil, I raq.

** Department of I nternal Medicine, College of Medicine, Hawler Medical University, Erbil, I raq. 
It is synthesized in the skin by the action of ultraviolet irradiation ${ }^{4}$. Vitamin D3 has been found to have immunomodulatory actions. There is no relationship between season and incidence of RA, but the season may affect on disease activity. The mechanism behind this finding is unclear ${ }^{5}$. Recently reported an inverse association between disease activity and vitamin D3 in patients with early polyarthritis. ${ }^{6}$ This demonstrated a reduction in RA disease activity with vitamin D3 supplementation. ${ }^{6}$ The $25(\mathrm{OH})$ D-1-a-hydroxylase enzymes are expressed in many cells of the immune system including macrophages and dendritic cells. The 1, 25(OH) vitamin $D$ leads to inhibition of T-cell proliferation and decreases the production of Th1 cytokines IL-2, IFN-Y and TNF- $\alpha$. The VDR has been found in macrophages, chondrocytes and synoviocytes in rheumatoid synovium and sites of cartilage erosion in RA patients. ${ }^{7}$ Vitamin D3 deficiency is involved in the pathogenesis of RA, and activity of RA ${ }^{8,9}$ Vitamin D3 deficiency will be defined as 25 $(\mathrm{OH})$ vitamin D level below $25 \mathrm{nmol} / \mathrm{l}$ (10 ng/ $\mathrm{ml})$, vitamin D3 insufficiency will be defined as $25(\mathrm{OH})$ vitamin $D$ level $25-75 \mathrm{nmol} / \mathrm{l}$ $(10-30 \mathrm{ng} / \mathrm{ml})$ and vitamin D3 sufficiency will be defined as $25(\mathrm{OH})$ vitamin D level $75-250 \mathrm{nmol} / \mathrm{l}(30-100 \mathrm{ng} / \mathrm{ml}) .{ }^{10}$ No similar studies have been conducted before in Kurdistan region and the whole Iraq to the authors' knowledge. This study was designed to assess the relations between vitamin D3 with RA in patients living in Erbil city.

\section{Methods}

This case-control study was carried out in the Rheumatology and Medical Rehabilitation Department of Rizgary Teaching Hospital in Erbil city from April 2015 to March 2016. Fifty patients who fulfilled EULAR-ACR-2010 and ACR 1987 criteria for RA were chosen by a convenience method of sampling, and those patients who were on vitamin D3, chronic renal failure, diabetes mellitus, malabsorption, patients on enzyme induced drugs (rifampicin, oral contraceptive, carbamazepine, antiepileptic, haloperidol, phenobarbitone) were excluded. Fifty age matched controls were also chosen by convenience method of sampling who underwent a full history and physical examination and serology test (RF and Anticcp) to confirm that they are not affected by RA. Their mean age and standard deviation (SD) was $46.42 \pm 10.86$ years. Data were collected and recorded on a specially designed questionnaire after getting verbal consent from the patients. Five $\mathrm{ml}$ of venous blood was collected from all patients and controls by clean venipuncture using plastic disposable syringes. Blood was allowed to clot before centrifugation and serum were taken. Serum concentrations of vitaminD3 were tested using (cobas e 411, S.N=1222.22 VITD-T 05894913) Vitamin D3 was measured for each patient and control. Vitamin D3 deficiency were defined as $25(\mathrm{OH})$ vitamin D level below $25 \mathrm{nmol} / \mathrm{l}$ $(10 \mathrm{ng} / \mathrm{ml})$, vitamin D3 insufficiency were defined as $25(\mathrm{OH})$ vitamin $\mathrm{D}$ level 25-75 $\mathrm{nmol} / \mathrm{l} \quad(10-30 \mathrm{ng} / \mathrm{ml})$ and vitamin D3 sufficiency were defined as $25(\mathrm{OH})$ vitamin D level $75-250 \mathrm{nmol} / \mathrm{l}(30-100 \mathrm{ng} /$ $\mathrm{ml}) .{ }^{10}$ Effective sun exposure on vitamin D3 should be > 20 min. ${ }^{11}$ Walking exercise increases the level of vitamin D3 > $30 \mathrm{~min}$ daily. ${ }^{12}$ About drug history RA patient's treatment are (DEMARD alone, combined DEMARDs or DEMARD + Biological agent). ${ }^{13,14}$ The activity of disease was assessed by DAS28 and CDAI parameters. Based on DAS28 patients were graded as in remission $<2.3$, low active <2.7, moderate 2.7-4.1 and highly active $>4.1$ and for CDAl were entitled in to in remission $<2.8$, low active $<10$, moderate 10-22 and highly active $>22$. Erythrocyte sedimentation rate and latex test were done for the patients. The data were managed by Excel using Chi-square test. A $P$ value less than 0.05 was considered statistically significant. 


\section{Results}

A total of 100 participants enrolled in the study, the vast majority of them were female $(92 \%)$ and the female to male ratio was 11.5:1. The study involved 50 RA patients, with 50 age matched control groups. Their mean age and SD was $46.42 \pm 10.86$ years, ranging from 20 to 65 years. Figure 1 shows that $34 \%$ of patients were in the sixth decade and $32 \%$ were in the fifth decade of life. There was no significant statistical association between vitamin D3 level and participants' age $(P=0.84)$ as shown in Table 1 . There was a significant statistical association between vitamin D3 levels and study groups as $70 \%$ of cases had deficient vitamin D3 levels, while only $46 \%$ of control group suffered from vitamin D3 deficiency $(P=0.04)$ as shown in Table 2.

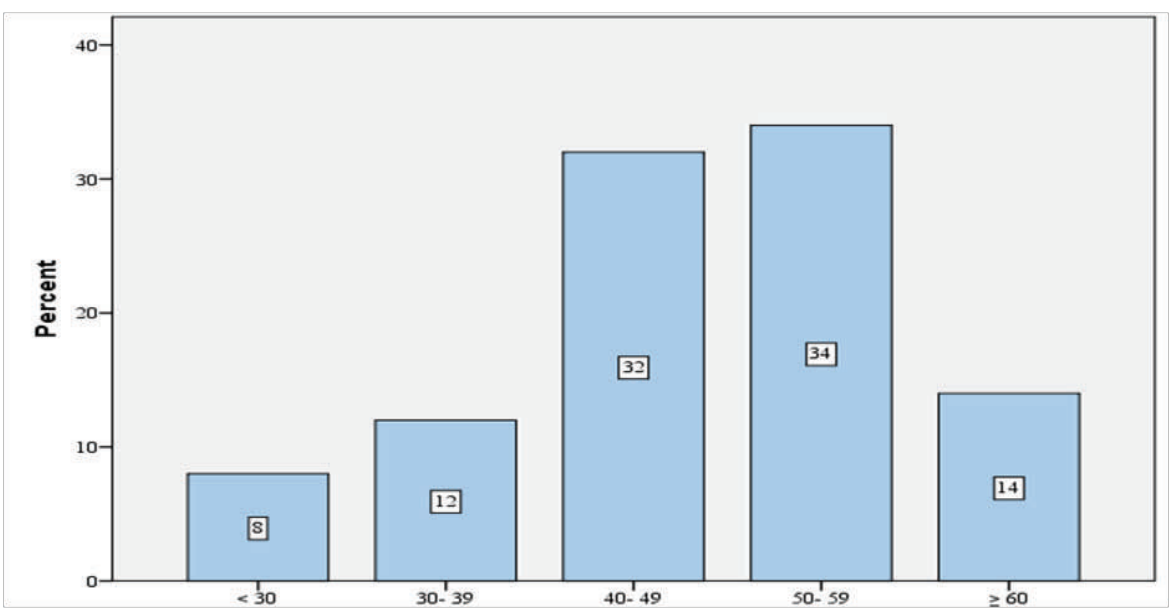

Figure 1: Age distribution of study sample in years.

Table 1: Relationship between Age and Vitamin D3

\begin{tabular}{lcccc}
\hline Vitamin D3 & N & Mean age & SD & $P$ value \\
\hline Deficient & 58 & 46.29 & 9.511 & \\
Insufficient & 28 & 47.32 & 12.520 & \\
Sufficient & 14 & 45.14 & 13.190 & 0.84 \\
Total & 100 & 38.75 & 35.221 & \\
\hline
\end{tabular}

Table 2: Relationship between study groups and Vitamin D3

\begin{tabular}{llccl}
\hline Parameters & Categories & \multicolumn{2}{c}{ Study groups } & P value \\
& & Cases & Controls & \\
\hline Vitamin $\mathrm{D}_{3}$ & Deficient & $35(70 \%)$ & $23(46 \%)$ & \\
& Insufficient & $9(18 \%)$ & $19(38 \%)$ & 0.04 \\
& Sufficient & $6(12 \%)$ & $8(16 \%)$ & \\
& Total & $50(100 \%)$ & $50(100 \%)$ & \\
\hline
\end{tabular}


There was a significant statistical association between the study groups and BMI, sun exposure and vitamin D3 concentrations. The average BMI of rheumatoid patients was higher than that of the control group $(P=0.01)$. The vast majority $(98 \%)$ of patients were exposed to less than 20 minutes in contrast to $72 \%$ of non-rheumatoid participants. $70 \%$ of cases had deficient vitamin D3 levels, while $46 \%$ of control group suffered from vitamin D3 deficiency $(P=0.04)$. There was a non-significant statistical relationship between study groups and walking. The majority of both groups were walking less than half an hour per day $(P=0.47)$. The details are shown in Table 3 . There was a non-significant statistical relationship between vitamin D3 levels and duration of disease, DAS28, CDAI and medications taken by the patients. Most of the rheumatoid patients with different vitamin D3 concentrations i.e. whether sufficient, insufficient or deficient levels had the disease for more than five years, with positive RF, moderate DAS28 and CDAI activities and history of taking methotrexate as their first drug of choice $(P>0.05)$ as shown in Table 4.

Table 3: Baseline Characteristics of Study Groups

\begin{tabular}{lcccc}
\hline \multirow{2}{*}{ Parameters } & \multirow{2}{*}{ Categories } & \multicolumn{2}{c}{ Study groups } & \multirow{2}{*}{ Cases } \\
& Mean \pm SD & $29.4 \pm 5.8$ & $27.3 \pm 7.1$ & 0.01 \\
\hline BMI & $\geq 20 \mathrm{~min}$ & $1(2 \%)$ & $14(28 \%)$ & 0.001 \\
Sun exposure & $<20 \mathrm{~min}$ & $49(98 \%)$ & $36(72 \%)$ & \\
Daily walking & $\geq 30 \mathrm{~min}$ & $9(18 \%)$ & $10(20 \%)$ & \multirow{2}{*}{0.47} \\
& $<30 \mathrm{~min}$ & $41(82 \%)$ & $40(80 \%)$ & \\
\hline
\end{tabular}

Table 4: Association between Vitamin $D_{3}$ and some Parameters of 50 Rheumatoid Cases.

\begin{tabular}{llcccc}
\hline Parameters & Categories & Deficient & $\begin{array}{c}\text { Vitamin } \mathrm{D}_{3} \\
\text { Insufficient }\end{array}$ & Sufficient & P value \\
\hline Duration of & $<2$ years & $6(75.0 \%)$ & $2(25 \%)$ & $0(0 \%)$ & \\
disease & $2-5$ years & $11(78.6 \%)$ & $3(21.4 \%)$ & $0(0 \%)$ & 0.23 \\
& $>5$ years & $18(64.3 \%)$ & $4(14.3 \%)$ & $6(21.4 \%)$ & \\
DAS28 & Low & $4(100 \%)$ & $0(0 \%)$ & $0(0 \%)$ & \\
& Moderate & $21(65.6 \%)$ & $6(18.8 \%)$ & $5(15.6 \%)$ & 0.63 \\
& High & $10(71.4 \%)$ & $3(21.4 \%)$ & $1(7.1 \%)$ & \\
DCAI & Low & $11(73.3 \%)$ & $2(13.3 \%)$ & $2(13.3 \%)$ & \\
& Moderate & $19(65.5 \%)$ & $6(20.7 \%)$ & $4(13.8 \%)$ & 0.84 \\
& High & $5(83.3 \%)$ & $1(16.7 \%)$ & $0(0 \%)$ & \\
Medications & MTX & $14(70 \%)$ & $4(20 \%)$ & $2(10 \%)$ & \\
& MTX + HCQ & $5(55.6 \%)$ & $3(33.3 \%)$ & $1(11.1 \%)$ & 0.86 \\
& MTX +Leflunomid & $6(100 \%)$ & $0(0 \%)$ & $0(0 \%)$ & \\
& MTX +Biological agents & $10(66.7 \%)$ & $2(13.3 \%)$ & $3(20 \%)$ & \\
& Positive & $19(63.3 \%)$ & $8(26.7 \%)$ & $3(10 \%)$ & 0.14 \\
& Negative & $16(80 \%)$ & $1(5 \%)$ & $3(15 \%)$ & \\
\hline \hline
\end{tabular}




\section{Discussion}

Rheumatoid arthritis (RA) is the most common chronic systemic polyarthritis. The etiology of RA is still unknown; many genetic and environmental factors play a role in the development of RA. Various studies has been made suggest that vitamin D3 deficiency increase the risk of developing autoimmune diseases like RA. ${ }^{15,16}$ This study was conducted with the objective to evaluate serum vitamin D3 levels in patients with rheumatoid arthritis and to compare it with controls and disease activity. In this study, vitamin D3 deficiency was more common in patients with RA than in healthy controls and even mean serum vitamin D3 level in patients with RA was found to be significantly low compared to healthy controls. $70 \%$ of cases had deficient vitamin D3 levels, while $46 \%$ of control group suffered from vitamin D3 deficiency $p$ value $<0.05$. As in Table 3.2 and this was near to the study done in Iran $^{17}$ and in Egypt ${ }^{18}$ in which the mean vitamin D3 serum values were $83.74 \pm 46.45$ $\mathrm{nmol} / \mathrm{L}$ in $\mathrm{RA}$ patients and $46.53 \pm 34.07$ $\mathrm{nmol} / \mathrm{L}$ in healthy volunteers. Another research done in China $(2014)^{19}$ also in agreement with our research but the result was less than what was in Iran and Egypt, this is might be due to sample size or geographical distribution, Vitamin D3 deficiency was more prevalent in RA group compared with control group $(48.70 \%$ vs. $30.00 \%, P<0.05)$. Serum vitamin D3 levels were lower in RA group (19.46 \pm 8.20 $\mathrm{ng} / \mathrm{mL})$ than control group $(23.18 \pm 6.71 \mathrm{ng} /$ $\mathrm{mL})(P<0.05)$. A research which has been made in Egypt $^{20}$ did not agree with our study as the result was vitamin D3 deficiencies was similar in both RA patients and controls $(99.1 \%$ versus $100 \%)$. Although, the mean serum vitamin $D_{3}$ level was less among RA patients than among controls, but there was no statistically significant difference $(5.98 \pm 6.8 \mathrm{nmol} / \mathrm{l}$ versus $8.4 \pm 9.6 \mathrm{nmol} / \mathrm{l}, P=0.06)$. Vitamin D3 deficiency might be endemic in Egypt. This may be attributed to decreased sun exposure (conservative dressing culture, wearing of veil and muffler, and/or avoidance of exposure to hot sunny weather). In our research there is no relation between serum vitamin D3 and disease activity which measured by DAS28 and CDAI, in both of them I took (VAS) patients assessment of disease activity which may have affected the result of disease activity. And this result supported by Craig, et al. ${ }^{21}$ which failed to discover a statistically significant association between vitamin D3 and DAS28 following multivariate adjustments in recent-onset rheumatoid arthritis patients. Cutolo, et al. $^{22}$ found a remarkable negative correlation between vitamin D3 and DAS28 in summer only in Southern European (Italian) patients and in winter in northern European (Estonian) patients, but no significant differences with respect to vitamin D3 values between Estonian and Italian RA patients and their controls. Research which doesn't agree with my result in disease activity and vitamin D3 are in an open-labeled randomized trial comparing triple disease-modifying antirheumatic drug (DMARD) therapy and 500 IU vitamin $\mathrm{D} 3$ + calcium combination versus triple DMARD and calcium alone by Gopinath et al., low levels of serum vitamin D3 were related to moderate-high disease activity in and supplementation of 500 IU of vitamin D3 daily was given to previously DMARD-naïve patients with early rheumatoid arthritis along with triple DMARD therapy showed significantly higher pain relief $(50 \%$ vs. $30 \%, P=0.006)$ in patient group than healthy controls. ${ }^{23-25}$ Low vitamin D3 levels may be associated with higher incidence of RA, as has already been mentioned by Song, et al. ${ }^{26}$ Other research done in India $^{27}$ which the result was against my research results, Thirty-one patients had high disease activity (DAS-28 score>5.1), 32 patients had moderate disease activity (DAS28 score 3.2-5.1) and 17 patients had low disease activity (DAS-28 score <3.2). Vitamin D3 level in high disease activity group was significantly low compared to 
vitamin D3 level in patients with low and moderate disease activity $(P<0.001)$ and vitamin D3 level had significant negative correlation with DAS28 score $(P<0.001)$. Vitamin D3 has immunoregulatory activity and vitamin D3 receptors are present in a number of cells of the immune system. ${ }^{28}$ Immunomodulation is mediated via (VDR) vitamin D3 receptor present on antigen presenting cell, activated T lymphocyte and activated B lymphocyte. Vitamin D3 leads to induction of regulatory $T$ cell and NK $T$ cell while vitamin D inhibits $\mathrm{TH} 1$ cell response, so vitamin D3 suppresses autoimmunity. RA is also a $\mathrm{TH} 1$ cell mediated disorder so vitamin D3 deficiency or insufficiency may be one of the several environmental causes leading to the development of RA. Monolagas et al. found that significantly greater proportion of seropositive RA patients $(76 \%)$ had lymphocyte possessing vitamin D3 receptor compared with healthy controls which was $(18 \%) .{ }^{29}$ Cherniak also studied that $84 \%$ prevalence of vitamin D3 insufficiency (serum level $<30 \mathrm{ng} / \mathrm{ml}$ ) in RA patients. ${ }^{30}$ The strong point it was a prospective case-control study in case and control there was age and sex match. There are some weak points in our study, the selection of cases was not through random sampling and certainly, there was selection bias. Also, DAS28 and CDAI which depend on patient scoring for disease activity as I mentioned it might affect the result also tenderness score may be exaggerated by the patient. More research required to know either vitamin D3increase the risk of RA development. About sun exposure it was less in the cases may be due to immobility, recurrent admission, and deformity of the upper and lower limb of the patients. This difference could be due to potential geographical factors, lifestyle and eating habits and lack of exercise, lack of enough sun exposure, obesity may effect on vitamin D3 absorption and inadequate dairy product, so my recommendation to the patients even controls are sun exposure should not be less than $20 \mathrm{~min}$ and vitamin D3 supplementation, Vitamin D3 insufficiency and deficiency among RA patients should be corrected.

\section{Conclusion}

Serum vitamin D3 levels are lower in rheumatoid arthritis patients and not associated with RA disease activity. Further studies with larger sample sizes and more standardized, unbiased methods are required to elucidate a causal role of vitamin D3 in RA and thus to bring about new approaches for prevention and treatment of this disease. Additional prospective, long-term studies are needed to comprehensively determine the role of vitamin D3 in developing RA and relation with disease activity. Vitamin D3 screening should be recommended for every RA patient in Erbil city.

\section{Conflicts of interest}

The authors report no conflicts of interest.

\section{References}

1. Kostoglou-Athanassiou I, Athanassiou P, Lyraki A, Raftakis I, Antoniadis I. Vitamin D and rheumatoid arthritis. Ther Adv Endocrinol Metab 2012; 3(6).

2. Shah A. Harrison's Principle of Internal Medicine. 18th ed. United States: McGraw Hill; 2012.P. 2738.

3. Scott DL, Wolfe F, Huizinga TW. Rheumatoid arthritis. Lancet 2010; 376 (9746): 1094-108.

4. Mason R, Sequeira V, GordonThomson C. Vitami $\mathrm{D}$ : The light side of sunshine. Eur $\mathrm{J}$ Clin Nutr. 2011Sep;65(9):986-93.

5. British Society for Rheumatology Biologics Register (BSRBR). Clinical aspects of vitamin $D$ in the management of rheumatoid arthritis .2008;36(8):442-6.

6. Jankosky C, Deussing E, Gibson R, Haverkos H. Viruses and vitamin $D$ in the etiology of type 1 diabetes mellitus and multiple sclerosis. Virus Res 2012; 163

7. Tetlow LC, Smith SJ, Mawer EB, Woolley DE. Vitamin $D$ receptors in the rheuamatoid lesion: expression by chondrocytes, macrophages and synoviocytes.Ann Rheum Dis 1999;58.

8. Song GG, Bae SC, Lee YH. Association between vitamin $D$ intake and the risk of rheumatoid arthritis:a meta-analysis. Clin Rheumatol 2012; 31.

9. Kim TH, Choi SJ, Lee YH, Song GG, Ji JD. Combinedtherapeutic application of mTOR inhibitor and vitaminD(3) for inflammatory bone destruction of rheumatoidarthritis. Med Hypotheses 2012; 79. 
10. Sharma R, Saigal R, Goyal L, Mital P, Yadav RN, Meena PD, et al. Estimation of vitamin $D$ levels in rheumatoid arthritis patients and its correlation with the disease activity. JAPI 2014; 62.

11. Pearce SH, Cheetham TD; Diagnosis and management of vitamin D deficiency. BMJ. 2010;340

12. Shuler FD, Wingate MK, Moore GH, Giangarra C. Sports health benefits of vitamin D. Sports Health 2012; 4.

13. Landewe RB, Boers $M$, Verhoeven AC, Westhovens R, van de Laar MA, Markusse $\mathrm{HM}$, et al. COBRA combination therapy in patients with early rheumatoid arthritis: long-term structural benefits of a brief intervention. Arthritis Rheum 2002; 46.

14. O'Dell JR, Leff R, Paulsen G, Haire C, Mallek J, Eckhoff PJ, et al. Treatment of rheumatoid arthritis with methotrexate and hydroxychloroquine, methotrexate and sulfasalazine, or a combination of the three medications: results of a two-year, randomized, double-blind, placebo-controlled trial. Arthritis Rheum 2002; 46.

15. Cantorna MT, Hayes CE, DeLuca HF. 1,25-Dihydroxyvitamin D3 reversibly blocks the progression of relapsing encephalomyelitis, a model of multiple sclerosis. ProcNatlAcadSci USA 1996; 93.

16. Kamen DL, Cooper GS, Bouali H, Shaftman SR, Hollis BW, Gilkeson GS. Vitamin D deficiency in systemic lupus erythematosus. Autoimmun Rev2006; 5.

17. Sahebarim M, Mirfeizi Z, Rezaieyazdi Z, Rafatpanah H, Goshyeshi L. 25(OH) vitamin D serum values and rheumatoid arthritis disease activity (DAS28 ESR).Caspian Journal of Internal Medicin2014;5(3).

18. Yassin A, Gareeb NA, Samy C. The rehabilitation between vitamin $D$ and disease activity in Egyptian patients with Rheumatoid Arthritis .international trends of immunity 2014;3.

19. Wang $Y$, Zhang $F$, Wang S, Serum Vitamin $D$ is inversely Associated with Anti-cyclic Citrullinated Peptid Antibody level disease activity in Rheumatoid Arthritis Patients. Arch Rheumatoid 2016;31.

20. Allam NT, EL-Waked MM, El-Abed DM, Dorgham DA, Prevalence of Vitamin D difficiency in Egyptian Rheumatoid Arthritis Patients: Correlation with disease activity, functional disability, and bone mineral density. Egypt Rheumatol Rehabil2014;41.

21. Craig SM, Yu F, Curtis JR, Alarcón GS, Conn DL, Jonas B, et al. Vitamin D status and its associations with disease activity and severity in African Americans with recent onset rheumatoid arthritis. J Rheumatol 2010; 37(2).
22. Cutolo $\mathrm{M}$, Otsa $\mathrm{K}$, Laas $\mathrm{K}$, Yprus $\mathrm{M}$, Lehtme R, Secchi ME, et al. Circannual vitamin d serum levels and disease activity in rheumatoid arthritis: Northern versus Southern Europe. ClinExpRheumatol. 2006; 24(6).

23. Borges MC, Martini LA, Rogero MM. Current perspectives on vitamin $D$, immune system, and chronic diseases. Nutrition 2011; 27(4).

24. Gopinath K, Danda D. Supplementation of 1,25dihydroxy vitamin D3 in patients with treatment naive early rheumatoid arthritis: a randomised controlled trial. Int $\mathrm{J}$ Rheum Dis 2011;14(4).

25. Cutolo $M$, Otsa K, Laas KM, Lehtme $R$, Secchi M, Sulli A, et al. Circulating vitamin D serum levels and disease activity in rheumatoid arthritis: Northern versus Southern Europe. ClinExpRheumatol 2006; 24(6).

26. Rossini M, MaddaliBongi S, La Montagna G, Minisola G, Malavolta N, Bernini L, et al. Vitamin $D$ deficiency in rheumatoid arthritis: prevalence, determinants and associations with disease activity and disability. Arthritis Res Ther 2010; 12 (6).

27. Sharma R, Saigal R, Goyal L, Mital P, Yadav R, Meena $P$, et al. Estimation of Vitamin D Levels in Rheumatoid Arthritis Patients and its correlation with the Disease Activity.journal of the association of physician of INDIA2014;62.

28. Jones G, Strugnell SA, DeLuca HF. Current understanding of the molecular actions of vitamin D. Physiol Rev 1998; 78.

29. Manolagas SC, Werntz DA, Tsoukas CD, Provvedini DM, Vaughan JH. 1,25dihydroxyvitamin D3 receptors in lymphocytes from patients with rheumatoid arthritis. J Lab Clin Med 1986; 108.

30. Cherniack EP. A Ray of Hope for Tender Joints: Vitamin D and Rheumatoid Arthritis. J Rheumatol 2011; 38 . 